\title{
Normative certitude for expressivists
}

\author{
Michael Ridge ${ }^{1}$ \\ Received: 27 February 2018 / Accepted: 17 July 2018 / Published online: 25 July 2018 \\ (c) The Author(s) 2018
}

\begin{abstract}
Quasi-realists aspire to accommodate core features of ordinary normative thought and discourse in an expressivist framework. One apparent such feature is that we can be more or less confident in our normative judgments-they vary in credence. Michael Smith has argued that quasi-realists cannot plausibly accommodate these distinctions simply because they understand normative judgments as desires, but desires lack the structure needed to distinguish these three features. Existing attempts to meet Smith's challenge have accepted Smith's presupposition that the way to meet the challenge is to show that normative judgments have more structure than they initially seem to have. I argue that accepting this presupposition is accepting too much. The orthodox view of certitude, insofar as there is one, understands certitude very roughly in terms of counterfactual betting behaviour. Counterfactual betting behaviour, though, is not in any useful sense a structural feature of a given judgment. It is rather a more holistic feature of a given agent's cognitive system. Insofar as it can meet the other challenges it faces, quasi-realism can characterize credences in terms of counterfactual betting behaviour and effectively say exactly what many realists will want to say about credences, thus meeting Smith's challenge much more directly.
\end{abstract}

Keywords Expressivism - Quasi-realism · Decision theory · Credence · Belief . Normativity $\cdot$ Metaethics

Quasi-realists aspire to accommodate core features of ordinary normative thought in an expressivist framework. One such feature is that people can be more or less confident in their normative judgments. I am more certain that pain is bad than I am that white lies are permissible. A plausible quasi-realist account of normative credence should follow ordinary practice and distinguish relative degrees of confidence (credences) from how valuable a given judgment takes an object of evaluation to be (importance). It should also distinguish both of these from the stability of the judgment in the face of further information and reflection (robustness). Michael Smith

\footnotetext{
$凶$ Michael Ridge

M.Ridge@ed.ac.uk

1 Department of Philosophy, University of Edinburgh, Edinburgh, UK
} 
argues that quasi-realists cannot plausibly accommodate these distinctions. He argues that (a) expressivists understand normative judgments as desires, but (b) desires lack the structure needed to distinguish these features (Smith 2002). Desires admit of counterfactual robustness and motivational strength, each of which could explain one of these three features, but there is no obvious third structural feature of desire left to capture the third. For example, a quasi-realist might analyse importance as strength of desire and robustness as the relevant counterfactual robustness of the desire. This would leave no obvious candidate feature of the desire to constitute the judgment's credence without conflating credence with either importance or robustness. The quasi-realist building blocks seem insufficient to accommodate all three features without conflating some pair.

Existing attempts to meet Smith's challenge try to meet it directly on its own terms; they implicitly accept Smith's presupposition that the way to meet the challenge is to show that normative judgments have the needed "structure." In this paper, I argue that this is already accepting too much, and that there is a better way to meet Smith's challenge-by arguing that quasi-realism is compatible with saying the same thing about credence that realists should say. A relatively orthodox conception understands certitude very roughly in terms of counterfactual betting behaviour. Counterfactual betting behaviour, though, is not a structural feature of a given judgment, but a holistic/counter-factual feature of an agent's cognitive system. This is the key to a more convincing rejoinder to Smith's challenge. ${ }^{1}$

I argue that quasi-realists can and should happily say that credence in a normative proposition is exactly the same as credence in a descriptive proposition. Or, rather, I argue that on a wide range of plausible realist views about the nature of credence in descriptive belief, quasi-realists can and should say that normative credence is just the same. ${ }^{2}$ My conclusion is, therefore, a modular one, in that it is compatible with a range

\footnotetext{
1 The basic idea that quasi-realists can say whatever realists say here has, to my knowledge, explicitly been floated in the literature only once, and in passing, by James Dreier, in a discussion of normative certitude on the blog PEA Soup (http://peasoup.typepad.com/peasoup/2009/01/expressivism-and-moral-certitude. html). Dreier's view was that neither the realist nor the quasi-realist can really explain what it is to "win" a bet on the truth of a fundamental normative proposition, and so both views have trouble here in precisely the same way. While I agree that both views face the same range of serious worries, I think that both views can do better than Dreier's passing comments suggest. Much of my positive account is therefore devoted to how we should understand counterfactual betting behaviour.

2 Note that there is one sense in which realists have a dialectical advantage over quasi-realists, even if my argument in the text works. It is open to realists to argue that because normative and descriptive judgment do not differ in their nature, but only in their content, then whatever the right story turns out to be about credence in descriptive judgment, the same story should work for normative judgment. The realist in this sense accommodates normative credences "for free." Well, not actually "for free" since it could turn out that there is no such thing as degrees of belief (certitude) and some have argued for this view, that belief is always all or nothing (see Sect. 4 below); moreover, given the numerous and deep difficulties in providing a plausible account of the metaphysics of credences in general (see below) this is a possibility we must take at least somewhat seriously. If, though, credences are metaphysically unproblematic for descriptive contents then the realist can get them "for free," it seems. By contrast, the quasi-realist must even then explain how normative judgment, which on their account is deeply discontinuous in its very nature admits of credences. It is only after we survey what are in fact the most plausible accounts of credence for descriptive judgments that we see that those particular accounts are, after all, fully compatible with quasi-realism—at least, that is what I will argue in the text. Although this point is correct as far as it goes, it is not obviously a deep objection to quasi-realism. The orthodox view of the dialectic between realists and quasi-realists is that
} 
of accounts of credence in descriptive propositions. I shall therefore not offer a fully developed positive theory; any such theory would be more tendentious than the more dialectical conclusion I aim to establish. Though the range of prima facie plausible accounts of descriptive credence compatible with quasi-realist deployment is wide, it is not unlimited. An interesting upshot of my account is that whether quasi-realists can take a relaxed attitude to normative certitude depends on whether we should posit both credences and "all-out" (sometimes called "binary") beliefs.

\section{Existing expressivist theories of normative credences and their problems}

There have been three main approaches to explaining normative credences in quasirealist terms in the literature: (a) motivational theories, (b) epistemic theories, and (c) vagueness/error-theoretic theories. I briefly discuss each of these in turn. Note first a generic reason for preferring the theory developed here, though. Insofar as the theory developed here enables the quasi-realist to say exactly what the realist says (or should say), it automatically has the virtues of theoretical elegance and unity that its rivals lack. The point about unity is especially important, since we can intelligibly make comparisons between credences in normative and descriptive propositions; we seem to need a "common coin" for this. Rival theories may struggle to provide this in virtue of offering different theories for each domain.

Motivational theories maintain that how much credence one places in a normative proposition is reducible to how motivated you are to act as the normative proposition entails you ought to act. A version of this theory can be found in several sources (e.g. Sepielli 2012) and was my previously my own preferred account (Ridge 2007). I will focus on my own earlier account here, though the problems I discuss generalize (with some modification) to other motivational theories. In previous work I defined certitude in terms of relative motivational strength and embeds this in a hybrid or "Ecumenical" Expressivist framework. Krister Bykvist and Jonas Olson raise several powerful objections to this view (Bykvist and Olson 2009). One objection to this approach arises from the need for a scale which goes from complete uncertainty (0) to complete certainty (1). As Bykvist and Olson emphasize, while we can treat complete indifference as equivalent to complete uncertainty, desire seems to have no "upper bound." This makes the very idea of complete certainty understood in terms of relative motivational strength problematic.

A second worry arises out of the theory's implications for how an agent's credences change in virtue of various changes to her motivational profile. Suppose I meet the ideal advisor, and his magnificent appearance enthrals me, causing my general desire

Footnote 2 continued

the realist gets certain things "for free" (e.g., truth-aptness, certitude, embedding) but must work hard to "earn" other features or explain them away (e.g., motivational internalism, the open question argument or ontological plausibility, the depth of deep normative disagreement) and vice versa. Even if the argument of the present paper works, the quasi-realist must "earn the right" to credences by arguing that they can deploy what are in fact the best accounts of credence in descriptive judgment. The quasi-realist, unlike the realist, has no ex ante guarantees here, just as they have no ex ante guarantee that they can earn the right to talk of normative truth, etc. Thanks to an anonymous referee for drawing me out on this dialectical point. 
to follow his advice skyrocket relative to my other desires. On the most natural reading of the motivational theory, this entails that I am suddenly more confident in all my normative judgments, but this is absurd. My confidence that (e.g.) knowledge is good for its own sake should not vary in direct proportion with how attractive I find my advisor!

Finally, changes to an agent's desires which are not any part of their normative judgments will also change the relative strength of the desires which are partly constitutive of her normative judgments. Bykvist and Olson give the example of falling in love. Falling in love will increase some of my desires which (let us assume) do not partly constitute my normative judgments. This means the relative strength of my normative judgment-constituting desires has thereby decreased. But this has the insane implication that falling in love makes me less confident in all my normative judgments.

So explaining certitude in terms of motivational strength faces numerous problems; indeed it was the difficulty in solving those problems that led me to look for the new approach developed in the present paper. What about epistemic approaches? These attempt to understand normative certitude in terms of how likely the agent takes it that a series of improving changes would lead them to reject the judgment. This approach is defended in Lenman (2003) and Blackburn (2009). Such judgments are epistemic in that the relevant notion of 'improvement' is itself an epistemic one. I have some sympathy for these approaches. However, one worry is that they are really theories of something other than credence. Perhaps one thing we mean in ordinary language by 'confidence' is epistemic-how likely we think it is that the judgment would withstand further investigation, or some such. This, though, is not the meaning of 'confidence' people interested in credences have in mind. Instead, they have in mind a notion of confidence which is much less intellectual than this-something like one's willingness to rely on the judgment when something you value is at stake. An epistemic theory of confidence therefore seems to be at best part of the story when it comes to what ordinary folks may have in mind when attributing degrees of confidence in propositions. Moreover, it is a conception that does not work well in contexts in which we are attributing different levels of confidence to agents who are not so reflective or conceptually savvy as to be making second-order epistemic judgments of the needed kind. We therefore need a less intellectually demanding notion of credence.

Finally, a more recent approach in effect treats normative uncertainty as (primarily) like the kind of ambivalence we have when applying a semantically indeterminate predicate to a borderline case. Here I have in mind the account developed by Eriksson and Olinder (2016). The version of expressivism they defend is best understood as a kind of hybrid or "Ecumenical" Expressivism, with both a non-cognitive and a descriptive element. The descriptive element is characterized as a kind of "classificatory disposition." Crucially, they argue, we can have fundamental uncertainty about whether a concept applies given semantic indeterminacy. This, they suggest, captures a lot of what we want from a theory of fundamental normative uncertainty. The idea is best illustrated with what are sometimes called "cluster concepts" which we supposedly grasp by understanding a cluster of loosely related criteria for the application of the concept rather than grasping individually necessary and jointly sufficient conditions. To their credit, Eriksson and Olinder recognize that not all cases of fundamental 
normative uncertainty are like this. Sometimes one endorses a standard, has no uncertainty about the application of the standard, yet one is still in some sense uncertain about the normative truth. In this case, they suggest, one's uncertainty is a secondorder belief about the certitude of one's normative belief which rests on an error-we wrongly think that the first-order normative belief is a fully representational belief and then form a second-order judgment about whether it might be mistaken.

The appeal to indeterminacy in the descriptive concepts which figure in someone's normative standards is original, but ultimately misguided. As Stephen Schiffer has argued, there is $a$ sense in which we have degrees of belief in virtue of something being a more or less borderline instance of some vague concept. Degrees of belief in this sense, though, are not well understood as uncertainty about whether the concept really applies. With uncertainty we have the sense that further investigation might in principle help firm up our view, say. It is not like this with a borderline case of a bald person. The crucial point, then, is that not all ambivalence is uncertainty. Here is Schiffer:

Sally's VPBs [vagueness-related partial beliefs] about Tom's baldness are no measure of any uncertainty she has about Tom's being bald. When her VPBs represent Tom as a borderline case of baldness, Sally is ambivalent as to how to judge Tom, but she doesn't take herself to be ignorant of the real state of affairs regarding Tom's baldness. (Schiffer 2003: p. 205)

This seems correct, and the point applies well in the normative case. People with fundamental normative uncertainty agonize about whether e.g. the meaningfulness of having a child is more important than the greater pleasure of a hedonistic lifestyle, whether they are morally required to give all their money to charity or reveal a friend's infidelity to his spouse, etc. We do not agonize over whether a borderline case of baldness should be called 'bald' though we do apply the concept with less ambivalence in some cases than we do in others. It is just a mistake to understand normative uncertainty as this kind of vagueness-related ambivalence. The other part of Eriksson and Olinder's theory suffers from the worries pressed against epistemic approaches-it makes normative uncertainty into an implausibly intellectual second-order phenomenon and even attributes error to those who make such judgments.

All the theories discussed in this section (which is to say all existing attempts at a quasi-realist conception of normative credences) try to meet Smith's challenge on its own terms. In the following section, I take a step back from Smith's framing of the debate and ask why quasi-realists cannot, instead, say exactly what realists should say about normative credences, at least on a wide range of specific theories of the nature of credences.

\section{What is normative certitude for realists?}

In presenting his challenge, Smith does not take a stand on the metaphysics of credences, limiting his remarks to their epistemology: 
...differences in subjects' levels of confidence is the sort of thing that gets revealed in how much they would be willing to bet on one outcome as opposed to another under circumstances of forced choice. (Smith 2002: p. 345)

Smith is not alone in neglecting explicit discussion of the metaphysics of credences. Those who have tried to meet his challenge have also not much explored this question. However, it is impossible to determine whether quasi-realists can adequately mimic or "steal" the realist conception without some idea of what that conception is (or should be).

Unfortunately, there is nothing like a clearly orthodox view of the metaphysics of credences. Broad agreement can be found only at the level of epistemology. In particular, there is broad agreement that a good method for determining how confident someone is in a proposition $\mathrm{p}$ is to find out what odds would induce that person to bet on the truth of $\mathrm{p}$. This picks up on the intuitive idea that we see how confident someone is by seeing to what extent they will "put their money where their mouth is." While it provides a useful rough heuristic, we should not understand "betting behaviour" narrowly, as including only actually placing monetary bets on the truth of propositions. Some people do not care about money, and others are averse to gambling. Moreover, for most people the value of money is not linear. ${ }^{3}$ A much broader notion of betting is therefore needed-one understood roughly in terms of what payoffs would induce the agent to risk a given cost on the truth of the proposition, where 'cost' and 'payoff' are understood in terms of things the agent cares about.

So far this is all very rough, but decision theory provides more precise characterizations. We begin by imposing certain formal constraints (e.g. transitivity) on the preferences of a rational agent. If we specify the constraints in the right way, Frank Ramsey proved that any agent whose preferences conform to those axioms can be represented as maximizing expected utility as given by a utility function $u$ and a probability function $p$. The idea is that $p$ is whatever is multiplied by utilities in such a representation.

Unfortunately, this does not tell us much about the nature of credences. A variety of views have been defended here, each with some plausibility. One influential view, championed by David Lewis and Donald Davidson, begins with the idea that there is nothing more to an agent's assigning a credence to a given proposition than its being true that the best interpretation of that agent entails that they do (Cf. Lewis 1974; Davidson 1970; see also Blackburn 1998; Dennet 1993). Call this "interpretationism." So far, of course, this tells us little about the nature of credences, since the idea of a credence is used in the characterization of what they are. Fortunately, the interpretationist can ultimately provide a more informative account by explaining the functional role of credences in the relevant sort of interpretation.

On interpretationism, the axioms of decision theory provide an a priori "grid" to impose on our interpretation of anyone as a rational agent (Cf. Blackburn 1998: p. 165). They constitute a grid in that they are ex ante constraints that any interpretation must respect. We begin with the idea that the agent's preferences are consistent and transitive. Consistency here entails that for all outcomes $a$ and $b$, either $a$ is weakly preferred to

\footnotetext{
${ }^{3}$ De Finetti's classic discussion seems to rely on monetary bets as primitives despite the obvious worries with this approach. See de Finetti (1990: pp. 75-76).
} 
$b$ (that is either preferred to, or at least as much as, $b$ ) or $b$ to $a$. Transitivity simply entails that if $a$ is weakly preferred to $b$ and $b$ is weakly preferred to $c$, then $a$ is weakly preferred to $c$. These assumptions are enough to guarantee that a utility function can be defined such that the expected utility of $a$ is at least as great as $b$ if and only if $a$ is weakly preferred to $b$. We then need to connect preferences with the agent's choices. We do this by stipulating that if an agent makes a choice, then "he or she is making choices as though he were equipped with a preference relation which has that choice preferred to others, in light of what else he believes about the situation." (Blackburn 1998: p. 164) We further assume that a rational agent can always be interpreted as choosing so as to promote the satisfaction of some preference. More specifically we interpret the agent as seeking to maximize expected utility. It is here that the theory provides a functional characterization of credences. The expected utility of a choice is equivalent to the sum of the adjusted utility of each of its possible outcomes, where the relevant adjustment is to discount the utility of each outcome in accordance with the agent's credence in the proposition "if I make this choice then this outcome will follow." Credences must be between 0 and 1 [inclusive] and the relevant discounting is simply taking the product of the agent's credence in the conditional linking the choice to the outcome and the utility of the outcome itself. The idea is that we use the axioms of decision theory and the assumption that the agent is maximizing expected utility to fix values for the agent's preferences, beliefs and credences as those which will elegantly explain his or her choice behaviour. No single piece of data about the agent's choice behaviour entails a particular interpretation; the procedure is more akin to solving a jigsaw puzzle than following an algorithm. An agent's credence in a given proposition $p$ is simply that mathematical value $n$ which is such that characterizing the agent's credence in $p$ as $n$ would figure in our best interpretation of the agent as maximizing expected utility. Credences are, in effect, nodes in a predictive/explanatory theory which elegantly explains and predicts the agent's behaviour. Obviously sometimes there will be significant underdetermination of theory by data, but this is seen as par for the course in this area of philosophy/decision theory.

Interpretationism comes in more than one variety. One important dimension of variation is whether facts about credences can be further reduced to facts about how an agent would behave in various hypothetical contexts. An interpretationist can allow that although the facts about credences of a given agent are nothing above and beyond what follows from the best interpretation of that agent, what follows from such interpretations can, in turn, ultimately be given a behaviouristic reduction (Cf. Jackson 1998). Behaviouristic reductionism is hardly mandatory, though. One might insist that supervenience does not entail reduction. Perhaps talk of credences is itself normative talk. Many have argued that talk of meaning and content is normative talk (Cf. Gibbard 2012; for an extended critique of this view, see Hattiangadi 2012). If this is right then quasi-realists should extend their approach to talk of meaning and content-and, indeed, Gibbard has done just this at length (Gibbard 2012). Once one takes a view like Gibbard's of talk of content in general, though, it is natural enough to take a quasi-realist view of talk of credences. Finally, one might take credences to be metaphysically primitive. I do not know of anyone who has adopted this view. Eriksson and Hajek argue that the concept of credence is a primitive one but do not argue that credences themselves are irreducible; in fact, they explicitly deny this (Eriksson and 
Hajek 2007: p. 205). Any such anti-reductive theory would seem to owe some account of why credences supervene on something like betting dispositions; it is not obvious how this challenge could be met. This is analogous to a familiar problem for moral non-naturalism - to explain how the putative non-natural moral properties supervene on the natural/descriptive/non-normative properties.

What these conceptions have in common is the idea that credences are characteristically revealed by counterfactual betting behaviour. Since explaining the intimate connection between credences and suitable counterfactual betting behaviour is common ground, it makes sense to pause over how "betting behaviour" should be understood in this context. As I argued above, 'betting behaviour' must be understood broadly. I bet on the truth of 'the drivers won't speed through the light' in choosing to cross the street while simultaneously believing that if I cross the street and drivers speed through the red light then I die, which is a huge disutility to me, whereas I believe that if I cross the street and they do not speed through the light then I will more conveniently achieve some end I value, but which is much less important to me than avoiding premature death. What we need, then, to make sense of betting in the relevant sense, are conditional beliefs whose antecedents are the conjunction of the proposition whose confidence is being evaluated and a proposition about some possible behaviour of the agent, and whose consequents are some outcome the agent cares about, and conditional beliefs whose antecedents are conjunctions of the negation of the target proposition and the proposition that the agent refrains from the relevant behaviour, and whose consequents are some outcome the agent cares about.

This is fine as far as it goes. An immediate complication is that the relevant conditional beliefs can themselves vary in certitude. Plausibly, how much a rational agent should risk on the truth of $\mathrm{p}$ should depend, in part, on how certain the agent is in that the truth of $\mathrm{p}$ will ensure that a given action will lead to a given outcome. Presumably we will need to analyse the agent's certainty in the relevant conditionals in the relevant nearby possible worlds in terms of yet more conditionals and betting behaviours in yet more possible worlds. This seems to lead either to an infinite regress of such conditionals or some kind of circularity. Eriksson and Hajek press this objection:

The betting interpretation is apparently circular, because your betting price regarding some proposition $\mathrm{X}$ is determined not just by your credence in $\mathrm{X}$, but also by a raft of your credences in other propositions (Eriksson and Hajek 2007: pp. 187-188)

This regress/circularity worry seems like a problem for all theories of credences canvassed above. ${ }^{4}$ Even the assumption that credences are metaphysically primitive needs to explain how their truth is linked to truths about counterfactual betting behaviour.

The problems do not end here, though. Another problem is that forming a conditional belief about payoffs can change your credence in the relevant proposition. As I type this, the credence I attach to the proposition that I will bang my head on the wall in the next minute is very low. If, though I were to come to believe that if I were to

${ }^{4}$ Cf. also Lance (1995). 
bang my head against the wall I would get some monetary payoff, then the credence I would assign to that proposition would go up. ${ }^{5}$

Putting these worries to one side, how does the conception of "betting behaviour" on offer apply to credences in normative propositions? On a naïve conception of "betting," the very idea of betting on a normative proposition is odd. Suppose a bookie asked you if you would like to bet on the truth of act utilitarianism. Even if you were quite confident about the falsity of utilitarianism, you would be puzzled by such an offer. Fortunately, the conception of betting behaviour on offer here is not so naïve as that, and perhaps can do better at making sense of the very idea of "betting on the truth of a normative proposition." What we need is the right sorts of conditional beliefs. For me to bet on the truth of the proposition that pleasure is good as an end, I must have some beliefs connecting the truth of that proposition and my possible behaviour in the right way with something I care about.

Presumably the relevant beliefs need not be ones I actually have. After all, in that scenario I might simply not have any beliefs of the right sort. If we insist on actual conditional beliefs, then in such a scenario we would have to say that my credence in the proposition that pleasure as an end is undefined. Such an approach threatens to posit far less in the way of determinate facts about credences than ordinary thought presupposes. We should, therefore, avail ourselves of facts about how I would behave in nearby possible worlds in which I have the needed belief(s). This obviously runs right into the worry that such beliefs will in some cases change my credences-see my discussion of banging my head against the wall above. However, those just are problems for any theory of credence.

The needed beliefs must be of the form "If I $\Phi$ in $C$ and $p$ is true then such and such payoff results," where ' $p$ ' is the normative content the agent believes in the actual world and whose credence we hope to measure. The trickier question is what sort of psychology we should posit when thinking about the nearest possible world in which the agent has such conditional beliefs. In particular, these beliefs will need to be based on something. Since we are interested in the nearest possible worlds in which the agent has the belief, they should be based on something that does not strike us as bizarre. Furthermore, the relevant conditional beliefs will ideally not be based entirely on the agent's certainty in some normative principle in conjunction with beliefs about the descriptive properties which figure in the antecedent of that principle. In that case, the conditionals are in effect equivalent to conditionals with purely descriptive contents, and will not help us assess certitude in normative propositions. Ideally, then, we need conditional beliefs where it is the truth of the normative proposition qua normative proposition (no matter what normative principle turns out to vindicate it, say) which licenses the move to the consequent.

Theological beliefs offer one potential way forward. Historically, one way people have taken the truth of normative propositions to be connected with things they care about has been via theological propositions. For example, I might believe in karma, and therefore believe that if lying is wrong, but I tell lies, then I will tend to not get what I want. Alternatively, I might believe that if lying is wrong and I tell lies then

5 Cf. Erikssson and Hajek (2007: p. 192) for a similar example to make the same point. 
I will be punished in the afterlife in some way. In such circumstances, telling a lie effectively is betting that lying is not wrong.

How confident am I that lying is wrong, then? This will be fixed by how much of what I care about I am disposed to risk on the truth of that proposition. We determine this by going to the nearest possible worlds in which I believe that the truth of the proposition determines how much utility I will derive from acting in one way rather than another and then "see what I choose" in that world. Of course, whether the reason for which one would endorse the relevant conditionals is a theological one in the nearest possible world may depend on the agent. For a committed atheist, this may well not be the nearest possible world. Fortunately, there are other ways to make sense of the relevant conditionals. A simplistic approach would be to assume that in the nearest possible world the agent cares about doing the right thing, say, and believes that the truth of the proposition in question bears on whether, in performing a given action he would thereby satisfy his preference to behave rightly.

For this account to work, the desire in question will need to be a desire de dicto to do the right thing and not a desire de re to do the right thing; otherwise we would be testing the agent's credence in the truth of the descriptive content they take to be rightmaking/constituting rather than their credence in the normative content itself. This might seem to create problems for a quasi-realist deployment of this conception of credences. After all, one aspect of the Frege-Geach problem is the need to explain how normative contents can figure as the contents of other propositional attitudes, like desire (see Schroeder 2008a, b: pp. 715-716 for discussion of this often-neglected aspect of the Frege-Geach problem). Dialectically, I can in principle here put this worry to one side because I will assume for the sake of argument that the Frege-Geach problem can be solved (see Sect. 3). My aim is to defend the conditional thesis that if quasi-realism faces no fatal objections on other fronts then it can handle normative credences as well as realism. However, because this aspect of the Frege-Geach problem is seldom noted, I will mention that I think hybrid forms of expressivism provide the most elegant solution. On, for example, my own preferred version of expressivism, "ecumenical expressivism," a desire to do the right thing is a hybrid state consisting of what he calls a "normative perspective," which is a kind of desire like state, and a desire to act in ways required by any standard not ruled out by that perspective (Cf. Ridge 2014). The more general idea is to fix the content of the relevant propositional attitudes in terms of some master non-cognitive attitude (e.g. normative perspectives) which fixes the agent's normative outlook in more general terms. Schroeder himself develops a similar view he calls "relational expressivism" and argues that it provides an elegant solution to the problem of these other propositional attitudes with normative contents in a way that is structurally analogous to my approach (see Schroeder 2013; see also Toppinen 2013 for a kindred approach). Other expressivist accounts of normative propositions that can serve as contents for other propositional attitudes, and which do not require a "hybrid" (ecumenical) approach can be found in Kohler (2017) and Schroeder (2011).

The preceding account relies on counterfactuals about what the agent would choose if they believed a given outcome depended on the truth of the relevant proposition. This approach coheres well with the emphasis on "betting behaviour." However, another approach eschews direct appeals to such counterfactuals about choice and instead simply adverts to agent's preferences between various gambles. Of course, since pref- 
erences plausibly dispose agents to make certain choices, this approach plausibly will incur commitments about counterfactual choice behaviour, so the difference between the two approaches may not be so deep. To avoid complications arising out of the possibility that an agent might have some preference as between the truth and falsity of the proposition whose credence is being assessed, Ramsey appealed to the idea of an "ethically neutral proposition"- a proposition $\mathrm{p}$ such that the truth of $\mathrm{p}$ is of no concern to the agent. Roughly, the idea is that a proposition $\mathrm{p}$ is an ethically neutral proposition for an agent $\mathrm{A}$ if and only if for any outcome $\mathrm{O}$ which is logically consistent with both $\mathrm{p}$ and not-p, the agent is indifferent between $(\mathrm{O}$ and $\mathrm{p})$ and $(\mathrm{O}$ and not-p). He argued that to measure a given agent's credences we needed there to be an ethically neutral proposition $\mathrm{p}$ such that the agent assigned a credence of .5 to $\mathrm{p}$. The idea was that we could explain what it is for the agent to assign such a credence in terms of the agent's preference between A if $p$ is true and B if $p$ is not true, where the agent does have a preference between outcomes A and B simpliciter. Given these assumptions, if the agent is indifferent between ( $\mathrm{A}$ if $\mathrm{p}$ is true and $\mathrm{B}$ if $\mathrm{p}$ is not true) and ( $\mathrm{B}$ if $\mathrm{p}$ is true and $\mathrm{A}$ if $\mathrm{p}$ is not true), the agent assigns a credence of .5 to $\mathrm{p}$. Ramsey argued that we could use this belief in an ethically neutral proposition to degree of .5 to measure the agent's value of various outcomes. The basic idea is to explain what it is for the difference between the value of one pair of outcomes A and B not to differ from the difference between the value of another pair of outcomes $C$ and D in terms of the agent having no preference between the following two lotteries: (a) A if $p$ is true and B otherwise and (b) C if $\mathrm{p}$ is true and D otherwise. With all of this in place, Ramsey showed how we can derive the agent's credences for any other proposition in terms of the agent's conditional preferences. ${ }^{6}$

The details of this approach are well known and not essential here. Suppose we take this approach to fixing credences in a given normative proposition. What we need for this machinery to apply is for the agent to have well defined preferences as between things like (a) certainty of $\$ 500$, and (b) $\$ 1000$ if lying is wrong and $\$ 100$ if lying is not wrong. This leads back to the issues facing the account couched more directly in terms of counterfactual betting behaviour. Plausibly, people do not actually have preferences as between (a) certainty of $\$ 500$, and (b) $\$ 1000$ if lying is wrong and $\$ 100$ otherwise. In fact, it is more than a little obscure what it would be for someone to have such a preference. What, though, would it be to offer someone such a choice in a way that they could take seriously? What we need, it seems, is some psychologically intelligible way in which an agent might think that the payoff of a given choice (like accepting a lottery) will depend on the truth of a normative proposition like "lying is wrong." That, though, takes us right back to the moves made above. We need the agent to have beliefs linking their choices to outcomes which differ in value depending on the truth of the relevant normative proposition. If we can make sense of such beliefs, then we can assign credences to normative propositions. I therefore tentatively conclude that the move to Ramsey's approach does not deeply change the dialectic. ${ }^{7}$ With this approach

\footnotetext{
6 F. P. Ramsey, “Truth and Probability," reprinted in Gardenfors and Sahlin (1988: pp. 19-47, esp. pp. 33-34). Whether Ramsey really needed the potentially tendentious idea of an ethically neutral proposition is controversial; see Elliot (2017) for useful discussion.

7 Thanks to Jamie Dreier and Wolfgang Schwarz for useful discussion here.
} 
in hand, I now turn to whether quasi-realism can deploy it without introducing further problems.

\section{Quasi-realism and normative credences}

It is not hard to see how old-fashioned forms of expressivism, like Ayer's emotivism, have trouble making sense of normative credences. If credence is just counterfactual betting behaviour, and normative judgment is simply a kind of feeling (e.g.) then what sorts of "bets" would constitute our normative certitude? Bets that we will continue to feel that way? That is hopeless. To be fair, Ayer himself was no quasi-realist, and he would have happily agreed that the concept of certitude does not apply to normative judgment any more than the concept of truth.

However, once we move from Ayer's emotivism to modern forms of quasi-realism, it becomes less clear why there is a problem in the first place. Smith's argument was that desire-like states lack the needed "structure," but that way of posing the challenge seems misguided. What we need as the basic building block to explain an agent's certitude in some normative proposition $\mathrm{p}$ is not, in any obvious sense, a structural property of the agent's judgment that p. Rather, we need the agent to occupy a sort of counterfactual profile, where that profile is understood in terms of betting behaviour given certain conditional beliefs. Why, though, can the quasi-realist not say exactly what the realist would say on this front?

It is crucial at this point to be clear about the quasi-realist's resources. First, quasirealism allows that normative judgments are truth-apt, and that many substantive normative judgments are in fact true. The standard strategy here is to defend a deflationist view of the truth predicate (Cf. Blackburn 1998; see Ridge 2014: ch. 9 for an approach that does not rely on deflationism). With truth, we have holding true, which is to say normative belief. Unlike Ayer, quasi-realists do not deny that there are normative beliefs in any ordinary language sense of 'belief'. Rather 'belief' should be understood as referring to a multiply realizable kind. Some beliefs are purely representational states, whereas other beliefs are non-representational, where the distinction between representational and non-representational states is a purely theoretical one. To underscore the ubiquity with which contemporary expressivists insist that moral and other normative judgments are beliefs in the sense given to 'belief' by ordinary language, here are some representative quotations from defenders of expressivism:

Since we can handle the ethical proposition exactly like any other, it is not mistaken to say that we voice belief in it, when we do. (Blackburn 1998: p. 79)

The important point...is that once we have this semantics in hand, we no longer need to describe expressivism as holding that there are no moral beliefs, or that moral sentences don't express beliefs. (Schroeder 2008a, b: pp. 139, 140)

So long as we do not build representationalism into the very definition of 'belief' (and we should not), we can allow that this judgment [a normative one] is a belief. (Ridge 2014: p. 119) 
I genuinely believe that pain is bad, and my expressivistic theory, filled out, explains what this believing consists in. (Gibbard 2003: p. 183)

Notably, Smith cites both Gibbard and Blackburn as targets of his critique (Smith 2002: p. 105), so it is fair enough to take their preferred characterizations of expressivism on board when thinking about how one might meet Smith's challenge.

Quasi-realists must also solve the Frege-Geach problem to be otherwise plausible. In that case we have not only simple atomic normative beliefs, but normative beliefs for any proposition whatsoever, no matter how logically complex. The quasi-realist can, if otherwise successful, therefore help themselves to conditional normative beliefs of the sort needed to model credence. Finally, quasi-realists need a conception of normative propositions, and several have been defended. In his earlier work, Allan Gibbard held that we can understand moral propositions as norm/world pairs (Gibbard 1990). In later work, focusing on the normative more generally, he understands normative propositions in terms of fact/plan worlds (Gibbard 2003). In the framework of ecumenical expressivism, I understand normative propositions as "cognitive event types" on a broad construal, building on work from Scott Soames (Ridge 2014: chapters 4 and 9), though he argues that the framework is compatible with other more conventional conceptions of propositions. Mark Schroeder argues that expressivists can understand normative propositions as pairs of properties where one property is at least as strong as the other in a certain sense (Cf. Schroeder 2008a, b: pp. 160, 161, but the view is much more fully spelled out in Schroeder 2015: pp. 92-96).

With these resources, it is not hard to see how a quasi-realist can say exactly what I suggested the realist should say about normative certitude. To see what credence I assign a normative proposition p, see what is true in the nearest possible world in which I believe conditionals of the form "If $\mathrm{p}$ and I $\Phi$ then outcome $\mathrm{O}$ will occur," such that $\mathrm{O}$ characterizes an outcome couched in terms of my utility function, and then see what I choose in light of those conditionals. If we specify the conditionals correctly, then we can use my counterfactual choice behaviour to work out at what odds I would accept a bet on the truth of $\mathrm{p}$. Those odds, in turn, fix my credence in $\mathrm{p}$ in the actual world.

As far as I can see, nothing in that story of counterfactual betting behaviour is incompatible with quasi-realism_assuming the latter succeeds on all other fronts. All we need is counterfactual truths about choices in scenarios in which the agent has the relevant conditional beliefs. As I have argued above, making good sense of those conditional beliefs is an essential part of the quasi-realist programme. Nor is there any reason to think a quasi-realist cannot accommodate the platitude that people will make different choices based on such beliefs in various counterfactual circumstances. Like the realist, the quasi-realist needs to make the relevant counterfactual beliefs intelligible in the sense of explaining the agent's reasons for believing them.

Obviously, this account will face all the problems facing a realist account. Most obviously, introducing the background assumptions needed to make the relevant belief intelligible may entail that the agent's certitude in the proposition in question is different in the relevant possible world, and hence betting behaviour in that world is not a good gauge of certitude in the actual world. If the nearest possible world in which I have the needed conditional belief is one in which many of my other beliefs are dif- 
ferent, then my credence in the proposition being evaluated may also vary. Hopefully there is some solution to this problem; otherwise there is a problem in the foundational theory of credences anyway. If there is a solution, though, it is not at all obvious why that solution will not be available to a quasi-realist as well. If there is not a solution, then the quasi-realist is no worse off than realists who implicitly rely on such accounts; after all, these problems could reveal that the very idea of a credence is paradoxical or incoherent.

With this result in hand, it is worth returning to the theories of the metaphysics of credences laid out in Sect. 1 to see whether all, some, or none of those theories is compatible with quasi-realism. Fortunately, quasi-realism is certainly compatible with all but one of these, and may be compatible with all of them. Interpretationism is compatible with quasi-realism. Interpretationism does not take on an ontological commitment to anything beyond behavioural dispositions and whatever ontological commitments come along with endorsing truths about counterfactuals. On one version of anti-reductive interpretationism, credence talk is normative talk. This would require a quasi-realist account of the meaning of claims about credences, which could raise worries about the ability of the quasi-realist to situate normative judgment in a fully naturalistic world. Indeed, it is a short step from a quasi-realist account of judgments about credences to a quasi-realist account of the contents of belief and meaning, since claims about what credence someone puts in a given proposition plausibly entail claims about what they believe (to some degree). Such a view of talk of the content of propositional attitudes would plausibly cohere best with a similarly normative view of content in natural language - a view independently defended by many theorists. That, in turn, raises a much more general worry as to whether the quasi-realist can give a quasi-realist account of our talk about the propositional attitudes, content and meaning in general. That, though, is again a perfectly general and separate worry about quasi-realism. Moreover, it is not as if it is obvious that the worry cannot be met; compare Gibbard (2012), which provides an extended argument that the quasirealist can and should explain talk of content and meaning in quasi-realist terms as well.

A functionalist account of credences is also compatible with quasi-realism. Functionalism in the relevant sense is the view that mental states are essentially characterized in terms of (a) their typical causes, (b) their typical causal connections to other mental states, and (c) their typical causal connection (in conjunction with other states, e.g. belief/desire pairs) to behaviour (Blackburn 1998: p. 56). In fact, quasi-realism itself fits very well with classical functionalism, emphasizing the distinctively practical role of normative judgments. Blackburn goes so far as to claim that quasi-realism just is a form of functionalism: "A full-dress title [for my view] might be 'non-descriptive functionalism' or 'practical functionalism'.” (Blackburn 1998: p. 77)

Finally, what about the view that credences are not only conceptually primitive but also metaphysically basic, irreducible properties? As I noted in Sect. 1, nobody defends this view of credences, though some have argued that the concept of credence is a primitive one. Moreover, insofar as this view is in some ways reminiscent of Moore's view of 'good', it may raise some of the same problems-problems which have historically animated quasi-realists. For example, how will the anti-reductive theory of credences explain why truths about credences somehow supervene on truths 
about counterfactual betting behaviour? This might seem quite mysterious-in the same way that quasi-realists find the supervenience of the normative on the descriptive mysterious. Suppose, though, that these concerns can be met. Is such a view of credences unavailable to quasi-realists? Perhaps, but it is not clear why. Crucially, one should not object by saying "credences apply only with respects to believed propositions, and there are no normative beliefs according to quasi-realism." As I emphasized above, quasi-realists do not deny that there are normative beliefs. Instead, the thesis would have to be that only beliefs whose contents are understood in purely representational terms can have credences qua irreducible property. Why, though, believe that? Some argument is needed here; nothing is obvious.

At this stage, one might object to the approach laid out here as follows:

Many of the views of normative credences on which the present argument relies entail that such credences are identical to dispositions to engage betting behaviour under suitable counterfactual circumstances or facts about the best interpretation of the agent or some such rather than states of mind. This, though, creates a problem for the quasi-realist which is at least not obviously a problem for realists. A variety of reasons support the view that expressivism about deontic modals (like 'ought' and 'must' when used in normative contexts) shares its fate with expressivism about epistemic modals (like 'might'). Indeed, some expressivists (including yourself!) have themselves recently emphasized the independently motivated semantic continuity of the epistemic and deontic modals (Cf. Ridge 2014, chapter one and Chrisman 2016; see also Kratzer 1977) and many of the objections to realism about normative facts seem to have plausible counterparts to realism about modal facts (e.g. worries about ontological parsimony apply at least equally well to modal realism as they do to moral realism). It is therefore no surprise that expressivists have argued that we should indeed understand 'might' and other epistemic modals in expressivistic terms; here not as expressing pro-attitudes but as expressing credences. Seth Yalcin is perhaps the most well-known defender of this view; see Yalcin (2011). If, though, credences are e.g. dispositions to counterfactual betting rather than states of mind then they are not the right sort of thing to be expressed by a sentence or speech-act; it is states of mind, rather than dispositions to behave, which are expressed in the relevant sense. Crucially, this is not a problem, or anyway not a problem with equal force, for the realist, since a normative realist might well eschew expressivism about epistemic modals; indeed, a realist stance in both cases might seem to provide a more coherent theoretical package. ${ }^{8}$

This is an interesting objection, at least insofar as it seems right that the quasi-realist is under a kind of dialectical pressure to adopt an expressivist view of epistemic modals, whereas the normative realist is not. Fortunately, this pressure can be diffused. The quasi-realist reply should be to argue that it is a false dichotomy to think that on the proposed accounts credences are e.g. dispositions to engage in betting behaviour in such-and-such way rather than states of mind. Instead, the view on offer should be that to assign a credence of .5 to a proposition p just is to be disposed to engage in such-and-

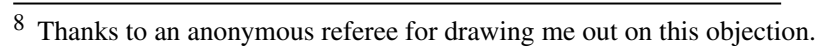


such betting behaviour. This would, after all, be very much in keeping with the broadly functionalist approach to states of mind that quasi-realists should anyway take (see above). On such accounts states of mind are, in effect, reduced to sets of dispositions. This is, in fact, very much in line with Yalcin's own account, since he argues that the belief that might-p is partly constituted by the agent's "question-sensitivity," where question-sensitivity in turn seems best understood in terms of dispositions to respond differentially to incoming information relevant to the question "p?" Indeed, Yalcin models sensitivity on the sensitivity of thermostats to temperatures, which is surely a matter of suitable dispositions (Yalcin 2011: p. 316). It is also in line with Blackburn's expressivist account of credences, which he at one point explicitly characterizes (in the case of irrational credences) as being "like bad dispositions that may nevertheless remain unrealized." (Blackburn 1993: p. 82) Gibbard is even more explicit, remarking at one point that we "could say in normative terms what dispositions would amount to having exact degrees of confidence." (Gibbard 2012: p. 119) Some realists might prefer to say that the state of mind is the categorial basis of the relevant dispositions (perhaps some neural state in humans) rather than the dispositions themselves, but as far as I can see, this account will also be available to expressivists - they, too, can say that a credence in a proposition is whatever categorial state constitutively explains the relevant betting dispositions.

I see no other obvious reason to think that these orthodox conceptions of credence for descriptive propositions could not seamlessly be carried over to the normative context a la quasi-realism. I therefore tentatively conclude that the proposed approach to normative credences is compatible with all the conceptions of credences laid out above, with the possible exception of the view that credence is metaphysically primitive. I further conclude that this approach faces no new problems not equally faced by a realist approach to normative credences. The theory also meets Smith's criteria-it distinguishes certitude from both importance and robustness. Importance will be part of the content of the judgment, which is not identical to certitude as analysed here. This is perhaps clearest on a hybrid expressivist view where the content of a normative judgement is constituted by an associated descriptive belief. On my own "ecumenical expressivism," (Ridge 2014), for example, importance is constituted by the content of a descriptive belief which partly constitutes the normative judgment, where how important the object of evaluation is by the agent's lights is how highly that object of evaluation is ranked by any standard not ruled out by the agent's normative perspective (a non-cognitive attitude which fixes the agent's general normative outlook). This is clearly distinct from the counterfactual betting profile which on the present account would constitute the agent's certitude in that normative content. On a non-ecumenical expressivist view, importance might simply be how strongly the agent desires the object of evaluation (or desires to desire it), where this motivational strength partly constitutes the content of the agent's judgment and is clearly distinct from the relevant counterfactual betting profile. Nor is robustness qua the resilience of the judgment in the face of new information and deliberation identical to certitude qua what you are willing to bet.

Even if it is conceded that the proposed account can draw the necessary distinctions at a conceptual and metaphysical level, one might worry that it does not do so in a way that explains the different roles that importance and certitude play in rationally 
motivating us. In fact, this is an often neglected aspect of Smith's original challenge; Smith argued that his own cognitivist metaethical theory could "accommodate the different roles that these features play in the explanation of action...in a straightforward and intuitive way," (Smith 2002: p. 315) and argued that expressivism struggles to do the same. How does the approach to normative certitude for expressivists have proposed here fare on this front? ${ }^{9}$

To some extent, I think this is a problem for everyone who aspires to account for the motivational efficacy of normative judgment, and it is not entirely clear that realists have it much easier here (I lack the space in this context to discuss Smith's own positive theory). I also think common sense gives us less clear-cut guidance than Smith seems to presume, and we need some common sense fixed points to test competing theories. In general terms, common sense tells us that the more valuable something is taken to be, the more motivated the agent should be by it, all else being equal. Equally, the less certain the agent is that the object of evaluation is valuable (at all), the less motivated she should be by it, all else being equal. In many cases in which these two come apart, so that the agent is more certain that something is valuable than she is that something else is valuable, but at the same time judges that if the less certain value is valuable then it is more valuable, common sense at most predicts that the agent will likely feel conflicted (more on this below), but does not predict what she will or rationally should choose. We get somewhat clearer common-sense predictions if we focus on cases in which the agent is sure that two objects of evaluation are such that if they are both good then they are equally good, but at the same time is more certain that one of them is good; in that case, common sense predicts that the agent would choose the more certain good, all else being equal. We also get clearer common-sense verdicts in cases in which the two variables (importance and certitude) come apart in opposite ways with respect to two putative goods, but such that the difference in value is small but the difference in certitude is vast. In such cases, common sense predicts that the agent would choose the much more certain but slightly less valuable option, all else being equal. Fortunately, the account developed here makes plausible predictions in such test cases.

Consider the first sort of case. Suppose Jones thinks that a certain quantity of pleasure is good precisely as valuable as a particular achievement, and he has a choice between doing something that would generate that much pleasure or something that would constitute his having made that achievement. However, Jones is more confident that pleasure is good (at all) than he is that the achievement is good (at all), assigning the former a credence of .9 and the latter a credence of .7. On the sort of expressivist theory proposed here, insofar as Jones is fully rational, he will choose the pleasure. Why? Given expressivism, he will have some motivation to perform both actions in virtue of deeming them good; or, anyway, he will insofar as he is fully rational (hybrid forms of expressivism can allow for local failures of motivation; Cf. Ridge 2007). To be independently plausible, the expressivist theory should entail that these motivations should be equally strong, all else being equal, given that Jones takes each option to be equally good. Why, then, would a rational agent choose the more certain good, given the expressivism and the account of certainty on offer here? If we assume that Jones

9 Thanks to an anonymous referee for drawing me out on this interesting issue. 
has a de dicto desire to do what is best (or anyway not to forego choose a worse option without some justification), then the theory predicts that this desire will tip the scales in favour of the more certain option. ${ }^{10}$ Why? Jones' greater certitude that pleasure is good entails, on the approach defended here, that in nearby possible worlds in which he desires to do what is best and believes, "pleasure and achievement are the only putative goods in play, so (b) if pleasure is good and achievement is not good and I choose pleasure over achievement then I do what is best, while (c) if pleasure is not good and achievement is good and I choose pleasure over achievement then I fail to do what is best, and (d) if neither pleasure nor achievement is good or both are good then I do what is best no matter what I choose," Jones will choose pleasure. He will choose pleasure in such worlds because he is, by definition, on the proposed account, more disposed to risk something he values on the truth of 'pleasure is good' than he is on the truth of 'achievement is good', given the stipulated certitudes. Given that he values choosing what is best, it follows straightaway that he will choose pleasure over achievement in such a case. Now just assume that in the actual world Jones has a desire to do what is best and also has the relevant beliefs (and, given the set-up, the beliefs are quite rational for him to have, after all). In that case Jones will choose pleasure over achievement, just as common sense predicts he should.

Of course, this account does help itself to the idea that the agent has a de dicto desire to do what is best (or something roughly equivalent). Someone sceptical about the proposed theory might take issue with the dialectical validity of this assumption. In fact, though, it is totally orthodox that an agent's certitude in a given proposition will only influence the agent's choices if by the agent's lights the truth of that proposition bears on how to achieve something the agent cares about; that is, that figures in the preferences which define their utility function. It is not clear why this orthodoxy should not apply in the case of normative propositions too. Moreover, it is very plausible that most people do have at least some desire de dicto to do what is best (not necessarily morally best, but best all things considered), or anyway to avoid choosing a lesser good without some justification. One interesting upshot of this account is that in some cases normative motivation will come entirely from the normative judgment itself and will, given expressivism amount to motivation via a desire de re for the right and the good, while in other cases (those involving competing goods with differential certitudes), at least some of the motivation will (typically) stem from a desire to de dicto for the right and the good. Although I lack the space to discuss this complex issue here, I think this upshot casts interesting new light on another challenge from Michael Smith, in this case a challenge to motivational externalists. Smith argues that there is something implausibly "fetishistic" about desiring the right de dicto rather than de re (Smith 1994: p. 76) The account just sketched instead implies, plausibly to my mind, that although normative motivation de re is primary, rational agents need normative motivation de dicto to help make rational choices in certain cases with conflicting goods.

This approach also yields welcome results in cases in which importance and certitude come apart in opposite ways with respect to two putative goods, but such that the difference in value is small but the difference in certitude is vast. Suppose Jones

\footnotetext{
10 For some discussion of why I can here reasonably presume that expressivists can make sense of such desires, see my discussion of de dicto desires with normative content above.
} 
thinks a hedonistic life with no achievement is good to degree n, while the life of a struggling artist filled with achievement but almost no pleasure is good to degree $\mathrm{m}$, where $m$ is only very slightly greater than $n$. However, Jones is far more certain that pleasure is good at all than he is that achievement is good at all; he assigns a credence of .99 to the former and a credence of only .55 to the former. In that case, common sense predicts that Jones will choose a hedonistic life if these are his only options. If we again help ourselves to the assumption that Jones has a de dicto desire to do what is best, the account on offer here also predicts that Jones will choose hedonism; or rather, if his desire to do what is best is not pitifully weak then this is what he will chose. Abstracting from the differences in certitude, Jones should have a very slight preference for the life of achievement, since he does (barely) deem it better. Given his vastly greater certitude in the value of pleasure, though, so long as he has a desire de dicto to do what is best which is stronger than this very slight first-order preference for the life of achievement, the theory on offer here predicts that he will choose hedonism. The reasoning has the same structure as in the first example. Jones will (implicitly) recognize that he stands a much greater risk of missing out on something he values (doing what is best) if he chooses the life of a struggling artist. The desire de dicto will therefore guide him to choose hedonism, again corroborating common sense.

Finally, what about cases in which importance and certitude come apart in opposite ways with respect to two putative goods, but where neither option is clearly dominant. Here common sense suggests nothing clear cut beyond the vague idea that the agent should feel conflicted. Again, the theory on offer here yields this consequence, given a desire de dicto to do what is best. This will yield some first order motivation for the putatively greater good and some second-order motivation (via the de dicto normative desire) for the lesser but more certain good, and for the same sort of reasons as those discussed in the preceding cases. Taking it as common ground that conflicting desires tend to make the agent feel conflicted, the right result is again secured.

A final challenge for the approach developed here is how it can vindicate rational constraints on credences which issue either from common sense or decision theory. I lack the space for a full discussion of all the relevant norms from decision theory, here, but I can at least provide some license for optimism on this front. One tempting way of developing the worry that the proposed theory draws on the fact that for an agent to assign a credence to a given proposition, the counterfactual truths about that agent must be such that the odds at which the person would accept a bet on the truth of $\mathrm{p}$ is relatively constant. Why should this generally be true? Perhaps the odds at which I would accept such a bet in the relevant sense are chaotic- "all over the map." If so then the account just sketched will entail an implausibly rampant indeterminacy in credences. Moreover, the realist might seem to have a better story to tell here, in virtue of some norm that applies only to genuinely representational beliefs. In fact, it is hard to see how the realist has any advantage in explaining why there will in general be any consistency in the odds at which a given agent will accept such a bet. Crucially, the usual argument given in the literature for the rationality of being consistent in this way is a purely practical argument. Insofar as you are not consistent in this way, you will be vulnerable to a "Dutch Book." 11 Insofar as that argument works to establish

11 See Ramsey (1988) for the classic statement of this point. 
that practical rationality can explain why people's counterfactual betting behaviour is consistent in the needed way, it will work whether we understand the beliefs in question as representational or otherwise. Once again, there may well be problems here, but they are problems for everyone and not especially for a quasi-realist.

\section{Binary belief and degrees of certitude}

One important question I have not yet addressed is how expressivists should understand the relationship between credences and "binary beliefs," where the latter does not admit of degrees. What are the available views of this distinction more generally? One view is that "binary belief" is credence above some threshold - the "Lockean" view. On a classical Lockean view, there is an absolute threshold which holds across all contexts. Modern Lockeans hold that the threshold varies between contexts. The Lockean view is a kind of monism, insofar as ultimately all the doxastic facts are facts about credences. An even more radically credence-first monism is eliminativism, which denies that there are such things as full belief at all (Cf. Jeffrey 1970). A diametrically opposed form of monism holds that we should abandon credences altogether and just stick with binary belief. The work that is supposed to be done by credences might, on this view, be done by further binary beliefs_-binary beliefs about the probabilities of propositions believed. In addition to these two forms of monism, there is the dualist view which holds that binary belief and credences are both real but neither is reducible to the other.

Unfortunately, each of these views faces powerful problems. Dualism has certain attractions, but it seems to posit two entirely separate cognitive systems, one of which reaches practical decisions via binary beliefs and standing intentions, the other of which reaches practical decisions via credence assignments and preferences/utility functions. Such a view (a) seems highly inefficient, and so unlikely on its face to have evolved, and (b) potentially incoherent insofar as these two systems might reach contradictory verdicts about what to do in a single choice context. ${ }^{12}$

Monism also faces serious problems. Consider first the naïve Lockean view which reduces binary belief to credence above some context-invariant threshold. Not only does fixing any particular threshold seem highly arbitrary, there are in principle problems with any threshold which falls below 1 . A standard objection is that for a lottery with enough tickets you will then count as believing that your ticket has lost. From this, plus the legitimacy of that belief that all the other tickets lost, you can infer that all the tickets lost, but you also know that one ticket is the winner. Obviously, a lot more can be and has been said about this, nor is this the only problem for the naïve Lockean view. However, it is enough to convey at least one important challenge for this form of monism. ${ }^{13}$

\footnotetext{
12 Weisberg tries to meet these challenges (Cf. Weisberg forthcoming) but I cannot do justice to his account here.

13 Cf. Leitgeb (2013) and Leitgeb (2014). See also Spohn (2012) and Smith (2016). Another worry about the Lockean approach is that our practices of holding people morally responsible presuppose a more robust notion of binary belief; see Buchak (2014). For discussion of how views on which the threshold varies with context are also problematic, see Schroeder and Ross (2014).
} 
What about the opposite form of monism, which does without credences? An obvious worry here is that agents $d o$ at least sometimes seem to act to maximize their expected utility. Moreover, interpreting talk of confidence in terms of the agent's beliefs about the probability of the other things they believe seems too intellectual and second-order. Non-human animals and young children can sometimes usefully be interpreted as acting to maximize expected utility and this does not seem well understood by their deploying second-order beliefs about probabilities.

The upshot is that it is unclear whether we should posit both credences and binary belief or only one but not the other. Nor is it clear how the two are related. Ideally, a quasi-realist take on normative certitude would therefore be "ecumenical" in the sense of being compatible with at least a wide range of the reasonable views still in play here. Obviously, a form of monism which rejects credences altogether would make short work of Smith's challenge! If there is no such thing as degrees of certitude then the quasi-realist is under no pressure to accommodate normative certitude. What about the other form of monism -credence-only monism? I think it is unclear how a quasi-realist could coherently hold this view. Why? Because existing quasi-realist theories are, implicitly, theories of what binary normative judgment $i$. This is never made explicit, but it seems like the most obvious construal, not least because these theories make no appeal to the idea of degrees of certitude as their most basic concept. The quasi-realist theory of normative judgment seems tailor made to do the work that binary belief is typically taken to do. In particular, one of the dominant views of binary belief is that it functions to limit what possibilities we take into account when reasoning. To this extent, binary belief is often thought to do the cognitive work that intention does in the purely practical sphere. As Michael Bratman argues, we need intentions to avoid constantly reconsidering alternatives, calculating utility and adjusting our plans. Jacob Ross and Mark Schroeder argue for this parallel in Ross and Schroeder (2011). They then argue that we can think of what I am calling binary belief as "treating as true in reasoning," where that effectively means "treating as certain." (see also Frankish 2009). It is not hard to see how certain prominent quasi-realist theories characterize normative judgments as being much more like binary belief in this sense than they are like a credence assignment. Gibbard's work is especially clear on this. Gibbard characterizes normative judgments as being plans, where plans are a kind of intentions - where intentions are, of course precisely the practical analogue of binary representational beliefs according to Ross and Schroeder. Moreover, the point of our normative concepts, according to Gibbard, is to settle the thing to do (Gibbard 2003). This seems very much like precisely the job description for a binary belief we find in Ross and Schroder. A similar conception can be found in Ridge (2014), where "normative perspectives" also function to settle the thing to do, and indeed where the normative is defined in terms of settling the thing to do. We can see normative judgments as binary beliefs in something like the sense given by Ross and Schroeder - the quasi-realist simply provides a deeper theory of how these judgments function as they do in reasoning, but agrees that to be a (binary) judgment at all is to be poised to be treated as true in reasoning.

Insofar as quasi-realism just $i$ a theory of binary normative judgment, it is inconsistent with any form of monism which holds that there is no such thing as binary normative judgment. Perhaps there is some way to construe such theories as being 
theories of normative beliefs which just are credence assignments to normative propositions above some (possibly contextually set) threshold. To my mind, such a construal will be both hard to make intelligible and fits very poorly with the spirit in which such theories are put forward. I therefore tentatively conclude that quasi-realism cannot be combined with a "credence-first" monism.

Quasi-realism can, though, be combined with dualism. As I noted above, dualism has its share of problems, but I see no obvious reason to suppose any new problems would follow from the inclusion of normative judgments as understood by a quasirealist in a dualist framework. If this is right, then the debate about quasi-realism here should be fundamentally reoriented - the focus should be on whether "credence-first" monism is the right view of credence in general. If it is, then quasi-realism may be in trouble, but otherwise quasi-realism is fine on this front.

\section{Conclusion}

I have argued that quasi-realism can meet Smith's challenge by adopting exactly the same conception of certitude a realist adopts or should adopt. All theories of certitude face serious worries, and the quasi-realist deployment of those theories will inherit those problems. That, though, is just to say that the quasi-realist is just as badly off as the realist on this front. No obvious further worries for the quasi-realist arise on this front. If the arguments developed here are sound then, perhaps somewhat surprisingly, future work in this area should focus on the neglected juxtaposition of the debates over binary belief and credences and the debates over quasi-realism and normative certitude.

Acknowledgements Many thanks to Matthew Chrisman, James Dreier, Sebastian Kohler, Geoff SayreMcCord, and Wolfgang Schwarz for helpful comments on an earlier draft of this paper.

Open Access This article is distributed under the terms of the Creative Commons Attribution 4.0 International License (http://creativecommons.org/licenses/by/4.0/), which permits unrestricted use, distribution, and reproduction in any medium, provided you give appropriate credit to the original author(s) and the source, provide a link to the Creative Commons license, and indicate if changes were made.

\section{References}

Blackburn, S. (1993). Essays in quasi-realism. Oxford: Oxford University Press.

Blackburn, S. (1998). Ruling passions. Oxford: Oxford University Press.

Blackburn, S. (2009). Truth and a priori possibility: Egan's charge against quasi-realism. Australasian Journal of Philosophy, 87, 201-213.

Buchak, L. (2014). Belief, credence and norms. Philosophical Studies, 169, 285-311.

Bykvist, K., \& Olson, J. (2009). Expressivism and moral certitude. The Philosophical Quarterly, 59, 202-215.

Chrisman, M. (2016). The meaning of 'ought'. Oxford: Oxford University Press.

Davidson, D. (1970). Mental events. In L. Foster \& J. W. Swanson (Eds.), Essays on actions and events (pp. 207-224). Clarendon Press.

De Finetti, B. (1990). Theory of probability (first edition 1974) (Vol. 1). New York: Wiley.

Dennet, D. (1993). The intentional stance. Cambridge, MA: MIT Press.

Elliot, E. (2017). Ramsey without ethical neutrality. Mind, 501, 1-51. 
Eriksson, J., \& Olinder, R. (2016). Non-cognitivism and the classification account of moral uncertainty. Australasian Journal of Philosophy, 94, 1-17.

Eriksson, L., \& Hajek, A. (2007). What are degrees of belief? Studica Logica, 86, 183-213.

Frankish, K. (2009). Partial belief and flat-out belief. In Huber, Schmidt-Petri (Eds.) (pp. 75-93).

Gardenfors, P., \& Sahlin, N. (Eds.). (1988). Decision, probability and utility. Cambridge: Cambridge University Press.

Gibbard, A. (1990). Wise choices, apt feelings. Oxford: Oxford University Press.

Gibbard, A. (2003). Thinking how to live. Cambridge, MA: Harvard University Press.

Gibbard, A. (2012). Meaning and normativity. Oxford: Oxford University Press.

Hattiangadi, A. (2012). Oughts and thoughts. Oxford: Oxford University Press.

Jackson, F. (1998). From metaphysics to ethics. Oxford: Oxford University Press.

Jeffrey, R. (1970). Dracula meets wolfman: Acceptance vs. partial belief. In M. Swain (Ed.), Induction, acceptance and rational belief. Dordecht: Springer.

Kohler, S. (2017). Expressivism, belief and all that. Journal of Philosophy, 114, 189-207.

Kratzer, A. (1977). What 'must' and 'can' must and can mean. Linguistics and Philosophy, 1(3), 337-355.

Lance, M. (1995). Probability and acceptance. Philosophical Studies, 77, 147-179.

Leitgeb, H. (2013). Reducing belief simpliciter to degrees of belief. Annals of Pure and Applied Logic, 164, $1338-1389$.

Leitgeb, H. (2014). The stability theory of belief. Philosophical Review, 123, 131-171.

Lenman, J. (2003). Non-cognitivism and the dimensions of evaluative judgment. Brown Electronic Article Review Service. http://www.brown.edu/Departments/Philosophy/bears/homepage.html.

Lewis, D. (1974). Radical interpretation. Synthese, 27, 331-344.

Ramsey, F. (1988). Truth and probability (originally published in 1931). In Gardenfors and Sahlin (Eds.) (pp. 19-47).

Ridge, M. (2007). Ecumenical expressivism: The best of both worlds? Oxford Studies in Meta-Ethics, 2, 51-77.

Ridge, M. (2014). Impassioned belief. Oxford: Oxford University Press.

Ross, J., \& Schroeder, M. (2011). Belief, credence and pragmatic encroachment. Philosophy and Phenomenological Research, 2, 259-288.

Schiffer, S. (2003). The things we mean. Oxford: Oxford University Press.

Schroeder, M. (2008a). Being for: Evaluating the semantic program of expressivism. Oxford: Oxford University Press.

Schroeder, M. (2008b). What is the Frege-Geach problem? Philosophical Compass, 3, 703-720.

Schroeder, M. (2011). Two roles for propositions: cause for divorce? Nous, 47, 409-430.

Schroeder, M. (2013). Tempered expressivsim. In R. Shafer-Landau (Ed.), Oxford studies in metaethics (Vol. 8, pp. 283-314). Oxford: Oxford University Press.

Schroeder, M. (2015). Expressing our attitudes. Oxford: Oxford University Press.

Schroeder, M., \& Ross, J. (2014). Belief, credence and pragmatic encroachment. Philosophy and Phenomenological Research, 88, 259-288.

Sepielli, A. (2012). Normative uncertainty for non-cognitivists. Philosophical Studies, 160, 191-207.

Smith, M. (1994). The moral problem. Oxford: Oxford University Press.

Smith, M. (2002). Evaluation, uncertainty, and motivation. Ethical Theory and Moral Practice, 5, 305-320.

Smith, M. (2016). Between probability and certainty: What justifies belief. Oxford: Oxford University Press.

Spohn, W. (2012). The laws of belief. Oxford: Oxford University Press.

Toppinen, T. (2013). Believing in expressivsim. In R. Shafer-Landau (Ed.) Oxford studies in metaethics (Chap. 11, Vol. 8, pp. 252-282).

Weisberg, J. (Forthcoming). Belief in psyontology. Forthcoming in Philosopher's Imprint.

Yalcin, S. (2011). Non-factualism about epistemic modality. In A. Egan \& B. Weatherson (Eds.), Epistemic modality (pp. 295-332). Oxford: Oxford University Press. 